\section{GERENCIAMENTO DE RESÍDUOS SÓLIDOS DOMICILIARES EM ÁREAS URBANAS E RURAIS}

\section{RESUMO}

Devido às mudanças no paradigma de consumo mundial, tornou-se imprescindível o gerenciamento integrado de resíduos sólidos domiciliares, como prevê a Política Nacional de Resíduos Sólidos. Os resíduos gerados nas regiões urbanas variam de acordo com os índices de desenvolvimento local. $\mathrm{Na}$ propriedade rural, esta problemática é real e crescente, porém muito pouco estudada, nacionalmente e internacionalmente. No Brasil, do conhecimento dos autores, o presente trabalho representa o segundo artigo publicado em revista científica sobre a temática de resíduos domiciliares em propriedades rurais. Este estudo ressalta a importância de uma abordagem que contemple o planejamento de coleta seletiva de resíduos sólidos, assim como divulgação sobre as legislações vigentes, especialmente sobre a responsabilidade dos fabricantes pelo ciclo global de vida de seus produtos, tanto em áreas urbanas como também em áreas rurais. É necessário planejar e gerenciar adequadamente ações que assegurem saúde, bem-estar, economia de recursos públicos e melhoria da qualidade de vida das gerações atuais e futuras. Pela grande diversidade de resíduos, há necessidade de diferentes modelos de gerenciamento, para reciclagem e destino final adequado destes, especialmente em áreas rurais. Atualmente, os municípios brasileiros não dispõem de infraestrutura adequada para execução da coleta e, principalmente, não possuem informações precisas da periodicidade, qualidade e quantidade dos resíduos gerados nas áreas rurais para implementar um efetivo plano de gestão integrada. Gerenciar os resíduos domiciliares em áreas urbanas e rurais vai além de planejar a coleta seletiva, sendo imprescindível gerar novas legislações a fim de responsabilizar os fabricantes pelo ciclo global de vida de seus produtos.

PALAVRAS-CHAVES: Lixo; Coleta Seletiva; Resíduos Recicláveis.

\section{HOUSEHOLD SOLID WASTE MANAGEMENT OF URBAN AND RURAL AREAS}

\section{ABSTRACT}

Due to changes in the paradigm of world consumption has become essential the integrated management of household solid waste, as provided in the Brazilian National Solid Waste Policy. The waste generated in urban areas varies according to the indices of local development. In rural properties, this problem is real and growing, but much understudied, nationally as well internationally. In Brazil, according to the authors' knowledge, this work represents the second article published in scientific journals on the subject of rural household waste. This study emphasizes the importance of an approach involving the planning of selective collection of solid waste, as well as the disclosure about laws, especially about the responsibility of manufacturers taking care of the overall life cycle of its products, both in urban areas but also in rural areas. It's necessary manage actions to ensure health, welfare, public resource saving and improving the quality of life of current and future generations. Considering the wide variety of waste, it's necessary to use different management models, for recycling and suitable final destination of these, especially in rural areas. Currently, the Brazilian cities do not have adequate infrastructure for the execution of collects and do not have accurate information about the periodicity, quality and quantity of waste generated in rural areas to implement an effective integrated management plan. Managing household waste goes beyond of planning the selective collection. It's imperative to create a new legislation in order to impel responsibilities for the manufacturers for the overall life cycle of their products, both in urban as well as in rural areas.

KEYWORDS: Garbage; Selective Waste Collection; Recyclable Waste.

\section{ISSN 2179-6858}

\section{SECTION: Articles}

TOPIC: Saneamento e Tratamento de Resíduos

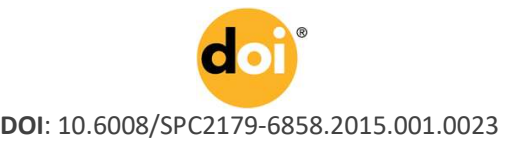

Dionatan Gerber

Universidade Tecnológica Federal do Paraná, Brasil http://lattes.cnpq.br/6775862862907410 dionatan gerber@hotmail.com

Luiz Pasquali

Universidade Tecnológica Federal do Paraná, Brasil http://lattes.cnpq.br/0503717994938418

pasquali@w/n.com.br

Fernando Campanhã Bechara

Universidade Tecnológica Federal do Paraná, Brasil http://lattes.cnpq.br/8651851040427432 bechara@utfpr.edu.br

Received: 02/02/2015

Approved: 14/10/2015

Reviewed anonymously in the process of blind peer.

Referencing this:

GERBER, D.; PASQUALI, L.; BECHARA, F. C. Gerenciamento de resíduos sólidos domiciliares em áreas urbanas e rurais. Revista Ibero-Americana de Ciências Ambientais, Aquidabã, v.6, n.1, p.293-306, 2015. DOI: http://dx.doi.org/10.6008/SPC2179$\underline{6858.2015 .001 .0023}$ 


\section{INTRODUÇÃO}

A geração e o destino final de resíduos sólidos são problemas mundiais, sobretudo, nas grandes cidades. Estima-se que no mundo inteiro são coletadas cerca de 2,5 a 4 bilhões de toneladas de resíduos sólidos por ano, incluindo o resíduo industrial. Quando abordado apenas os resíduos municipais este número diminui para 1,2 bilhões de toneladas por ano, sendo que o Brasil ocupa o sexto lugar nesta classificação (LACOSTE \& CHALMIN, 2006). O aumento da população mundial e a mudança de seus hábitos consumistas, a urbanização das comunidades e o aprimoramento de técnicas cada vez mais modernas de industrialização, resultaram num aumento significativo no volume dos resíduos gerados (DIAS \& MORAES, 2008).

Neste cenário, o problema dos resíduos sólidos domiciliares está ganhando uma dimensão perigosa em função da mudança do perfil dos resíduos. Com o avanço da tecnologia, materiais contaminantes, tais como plástico, pilhas, papel, lâmpadas fluorescentes e baterias são presenças cada vez mais constantes nos resíduos. $\mathrm{A}$ indústria considera diferentes aspectos ao confeccionar as embalagens de seus produtos, a saber: custo da matéria prima; facilidade de transporte, uso e segurança; durabilidade; volume de perdas; qualidade estética e atratividade do consumidor. No entanto, o destino final da embalagem raramente é planejado ficando o pós-consumo ou destinação final a cargo do serviço público (LOPES, 2006).

O processo de urbanização por que passam os municípios gera problemas inerentes ao seu desenvolvimento, dentre os quais os resíduos sólidos domiciliares ocupam destaque, gerando preocupação às administrações municipais, devendo ser um dos objetivos principais dos planos diretores municipais. Nos últimos anos, em função das transformações socioeconômicas e culturais globais, uma grande mudança nos hábitos alimentares ocorreu também na população domiciliar rural que passou a consumir mais produtos transformados e industrializados. Esta relação entre sociedade e natureza gera uma série de impactos ambientais negativos, diretos e indiretos. Se não forem adotadas medidas de gerenciamento para a sua redução, reutilização, reciclagem e destinação correta, em pouco tempo não haverá controle deste passivo ambiental. Contudo, a preocupação interinstitucional dos geradores dos resíduos, do Poder Público municipal e da legislação vigente nem sempre é convergente.

Considerando o paradigma de consumo mundial, evidenciou-se o planejamento do gerenciamento de resíduos sólidos domiciliares urbanos. Por outro lado, nas propriedades rurais, esta problemática ainda é muito pouco difundida, tornando-se uma lacuna no planejamento ambiental. Nesse sentido, este artigo apresenta uma revisão bibliográfica sobre os problemas ambientais gerados pelos resíduos sólidos domiciliares, incluindo seu tratamento e disposição, que são cada vez mais importantes para o almejado desenvolvimento sustentável, não só nas cidades, como também na área rural. 


\section{REVISÃO TEÓRICA}

\section{Classificação, Epidemiologia e Toxicologia dos Resíduos Sólidos}

De acordo com a Política Nacional de Resíduos Sólidos, Lei $n^{\circ} 12.305 / 10$, os resíduos sólidos têm sua classificação dividida quanto à origem (domiciliares, limpeza urbana, sólidos urbanos, estabelecimentos comerciais e prestadores de serviços, serviços públicos de saneamento básico, indústrias, serviços de saúde, construção civil, atividades agrossilvopastoris, serviços de transporte, mineração) e quanto à periculosidade (perigosos e não perigosos).

A Associação Brasileira de Normas e Técnicas por meio da NBR 10.004 classifica os resíduos sólidos quanto à periculosidade, estabelecendo categorias e características, e elencando-os como perigosos não inertes e inertes (ABNT, 2004). Consoni et al. (2000) classificaram-nos quanto à origem, a saber: domiciliar, comercial, varrição e feiras livres, serviços de saúde e hospitais, portos, aeroportos e terminais ferroviários/rodoviários, industriais, agrícolas e entulhos. Segundo Monteiro (2001), os resíduos sólidos podem ser classificados em resíduo público, resíduos domiciliar especiais, entulhos de obras e pilhas/baterias. Outra classificação dos resíduos, segundo CISAM (2006) estratifica-os em: resíduo animal, resíduo urbano, resíduo domiciliar, resíduo comercial e lixo público.

A disposição inadequada dos resíduos, caracterizada pela simples descarga sobre o solo ou águas, sem medidas de proteção ao meio ambiente ou à saúde pública, interfere na qualidade de vida da população. Este processo provoca diversos tipos de poluição: a visual (em virtude do local onde é disposto), a do ar (com as emissões de poeiras, gases e mau cheiro), a da água e a do solo (com a decomposição da matéria orgânica presente no resíduo que gera o chorume) (CISAM, 2006; OLIVEIRA \& FEICHAS, 2007).

Os resíduos domiciliares, como poliestireno (isopor ${ }^{\circledR}$ ), restos de tintas, solventes, aerossóis, produtos de limpeza, lâmpadas fluorescentes, medicamentos vencidos, pilhas e baterias, contêm significativa quantidade de substâncias químicas nocivas ao meio ambiente. Estima-se que existam de 70 a 100 mil produtos químicos sintéticos, utilizados de forma comercial na agricultura, na indústria e em produtos domésticos. Infelizmente, as consequências do efeito de seu uso na saúde humana e ambiental são dificilmente ou tardiamente notadas. As substâncias com metais pesados contaminantes como arsênio, chumbo, cádmio, mercúrio, cromo e manganês causam impactos negativos e acumulativos sobre o meio ambiente e, em especial, sobre o homem (HERMES-LIMA et al., 1991; BECHARA, 1996; OLYMPIO et al., 2010).

\section{Geração e Reciclagem de Resíduos nas Áreas Urbanas: Panorama Mundial e Brasileiro}

Quanto ao consumo, os países desenvolvidos, com somente $20 \%$ da população mundial, consomem diversos tipos de produtos e materiais, conforme demonstrado no Quadro 1 abaixo. 
Quadro 1: Consumo de materiais e produtos por países desenvolvidos.

\begin{tabular}{|l|l|}
\hline MATERIAIS/PRODUTOS & CONSUMO (\%) \\
\hline Alumínio e produtos químicos sintéticos & 85 \\
\hline Energia comercial, papel, ferro e aço & 80 \\
\hline Madeira & 75 \\
\hline Carne, pesticidas e cimento & 65 \\
\hline Peixes e grãos & 50 \\
\hline Água doce & 40 \\
\hline
\end{tabular}

Fonte: Adaptado de IDEC (2006).

A composição e a quantidade de resíduos gerados nas regiões urbanas variam de acordo com os índices de desenvolvimento dos países. Em média, os brasileiros geram metade dos resíduos gerados (em peso) pelos britânicos, alemães e italianos. Em relação ao cenário mundial, os maiores geradores de resíduos sólidos domiciliares estão entre os Estados Unidos e a Europa. É importante constatar que em países com baixa renda como Índia, Egito e países africanos, o índice de resíduos orgânicos varia de 50 a $80 \%$ em peso. Já em países com renda média como a Argentina, Taiwan, Singapura, Tailândia, este percentual varia de 20 a 65\%. Enquanto que, nas regiões com população de renda alta, como Estados Unidos, Europa Ocidental e China, o percentual varia de 20 a 40\%. Assim, sugere-se que quanto maior o Produto Interno Bruto (PIB) do país, maior é o consumo de papel por habitante e maior é a quantidade de resíduos gerados (LACOSTE \& CHALMIN, 2006). Portanto, denota-se a alta variabilidade dos índices de acordo com o grau de desenvolvimento dos países.

Enquanto na Suécia o índice de reciclagem (razão entre o total de materiais reciclados e a quantidade de resíduos sólidos gerados) é de 44\%, e nos Estados Unidos é de $32 \%$, no Brasil é de 12\%, e na Colômbia e Argentina é de apenas 5\% (JARDIM et al., 2010). De acordo com ISWA (2009), em 2007, 85 milhões de toneladas de materiais foram reciclados a partir de resíduos sólidos urbanos nos EUA (incluindo a reciclagem por meio da compostagem) alcançando uma taxa de reciclagem de 33,4\%. Em 1994, a União Europeia apresentou uma meta de taxa de reciclagem de resíduos de embalagens de 25\%, até o ano de 2001. Em 2004 essa meta foi aumentada para um mínimo de $60 \%$, até 2008 . Por conseguinte, a quantidade de resíduos de embalagens enviadas para aterros europeus diminuiu de 28 milhões de toneladas em 1997 para 21 milhões de toneladas em 2006, enquanto que o montante recuperado aumentou de 27 a 43 milhões de toneladas. Nota-se que mesmo que a geração europeia de resíduos de embalagens tenha aumentado menos resíduos têm sido destinados aos aterros (ISWA, 2009). Na Alemanha, apenas $2 \mathrm{~kg}$ de resíduos sólidos por habitante.ano-1 são destinados aos aterros, enquanto que na Suíça, este número é nulo sendo que aproximadamente $49 \%$ dos resíduos são incinerados (incluindo recuperação de energia) (EUROSTAT, 2010). Nos EUA são gerados $700 \mathrm{~kg}$.habitante${ }^{1}$.ano-1 de resíduos sólidos urbanos e na Índia, apenas $150 \mathrm{~kg}$ (LACOSTE \& CHALMIN, 2006). No Brasil, aterros sanitários e lixões recebem $251 \mathrm{~kg} \cdot$ habitante ${ }^{-1} \cdot \mathrm{ano}^{-1}$ de resíduos (JARDIM et al., 2010).

No Brasil, as embalagens de alimentos representam cerca de dois terços do volume total de resíduos sólidos gerados pela população, o que representa um desperdício anual de 6,3 bilhões de reais, ou 31.640 toneladas de materiais recicláveis (ou reaproveitáveis) que são 
descartadas (IDEC, 2006). Algumas cidades brasileiras, especialmente nas macrorregiões Sul e Sudeste - como São Paulo, Rio de Janeiro e Curitiba - alcançaram índices de produção de resíduos mais elevados, podendo chegar a $1,3 \mathrm{~kg}$ de resíduos sólidos. habitante ${ }^{-1} \cdot \mathrm{dia}^{-1}$, considerando todos os resíduos manipulados pelos serviços de limpeza urbana (domiciliares, comerciais, limpeza de logradouros, serviços de saúde e entulhos) (MONTEIRO, 2001). Dos 5.565 municípios existentes no Brasil, 57\% afirmam contar com iniciativas de coleta seletiva. Porém, ressaltamos que muitas vezes essas atividades de coleta seletiva praticada pelos municípios resumem-se à disponibilização de pontos de entrega voluntária à população ou na simples formalização de convênios com cooperativas de catadores para a execução dos serviços (CASTAGNARI, 2009). Levando em consideração a disposição final de resíduos nos municípios no Brasil, este último autor aponta que $38 \%$ possuem aterros sanitários, $31 \%$ possuem aterros controlados e $30 \%$ ainda apresentam lixões, sem planejamento de controle ambiental.

\section{Resíduos Sólidos Recicláveis na Área Rural: Panorama Mundial e Brasileiro}

No que se referem à área rural, as alterações nos padrões de consumo decorrentes da modernização da agricultura fazem com que cada vez mais sejam gerados resíduos domiciliares, além do descarte das embalagens de produtos utilizados nas atividades agrícolas. Os resíduos depositados inadequadamente provocam: poluição visual, prejudicando o turismo rural; degradação ambiental; poluição de corpos d'água; além da proliferação de insetos e roedores que causam doenças como dengue e leptospirose (FINATTO et al., 2005).

$\mathrm{Na}$ literatura internacional, ao contrário dos resíduos domiciliares urbanos, há raros artigos científicos sobre os aspectos quali-quantitativos da geração de resíduos recicláveis em domicílios rurais, sendo a maior parte dos trabalhos feitos em pequenos municípios e vilas, e não em propriedades rurais propriamente ditas. Estudos mais detalhados sobre a composição dos resíduos domiciliares rurais foram conduzidos na China. Neste país, Abduli, Samieifard e Zade (2008), relataram que em 21 aldeias rurais os resíduos foram distribuídos em: resíduo domiciliar e orgânico (42,49\%); resíduos de construção e demolição (11,70\%); papel e papelão (8,77\%); plástico (8,24\%); madeira (6,90\%); vidro (5,89\%); borracha e couro $(5,10 \%)$; e têxtil $(4,83 \%)$. Os autores ainda registraram uma média de 646,43g.dia ${ }^{-1}$.habitante ${ }^{-1}$. Chung e Poon (2001) mostraram que, na China, há grande apoio para a separação dos resíduos na fonte de geração, seja em comunidades rurais ou urbanas, e que a maioria das pessoas já estão empreendendo a separação, devido ao valor da venda dos materiais recicláveis. Nesse sentido, os decisores políticos se preocuparam com a forma de motivar a população a separar os resíduos para o bem estar da sociedade e como manter um eficiente mercado de recicláveis.

Stokoe e Teague (1995) indicaram que as áreas rurais dos Estados Unidos da América (EUA) enfrentaram muitas dificuldades com o ônus adicional de pobreza, isolamento geográfico, recursos limitados de pessoal do governo local, limitações financeiras, e outras restrições. Usando os conceitos de gestão integrada em comunidades rurais, os autores afirmaram que as 
comunidades estudadas mostraram que os gestores de resíduos sólidos conseguiram aplicar a gestão de resíduos apenas de uma forma pontual e fragmentada. Algumas comunidades se concentraram em apenas uma fase da integração da hierarquia de gestão de resíduos, tal como somente a coleta seletiva para reciclagem. Outras enfatizaram a coleta de um único material, tais como resíduos de plástico ou papel. Tais abordagens desconexas são geralmente motivadas por uma combinação de leis e regulamentos, dirigidos pela política e economia local. Em estudo realizado em uma área rural no Tennessee (EUA) por Jakus et al. (1997), apontou-se que na maioria dos casos, as comunidades rurais estão sujeitas aos mesmos regulamentos federais e estaduais quanto à geração de resíduos que nas comunidades urbanas. Porém, o sistema de coleta de materiais recicláveis nas áreas rurais são mais complexos, e para serem efetivos demandam ações específicas.

No Egito, El-Messery et al. (2009) assinalaram que a participação do setor privado na gestão de resíduos sólidos em áreas rurais é ainda muito limitada. Quanto aos impactos ambientais, relata-se que cerca de $73 \%$ dos resíduos sólidos gerados a partir das aldeias pesquisadas é jogado nas margens de corpos d'água, acumulados em torno das aldeias ou queimados em áreas abertas. Na Romênia, Capatina e Simonescu (2008) indicaram que o gerenciamento dos resíduos rurais deve ser conciliado entre o Poder Público e as famílias. Porém, grande parte das propriedades rurais ainda não dá a importância devida aos resíduos, pelo fato de avaliarem somente a pequena geração da unidade familiar e não contemplarem a soma de todas as unidades da comunidade.

Já no Brasil, a temática de gerenciamento de resíduos sólidos domiciliares na área rural é incipiente. Do conhecimento dos autores, há apenas as seguintes publicações: dois trabalhos apresentados em eventos por Dias et al. (2007) e por Oliveira e Feichas (2007); um trabalho técnico realizado por Breda et al. (2004); e o artigo científico pioneiro realizado por Martins, Andrade e Prates (2009). Estes últimos autores avaliaram seis famílias de um total de 24 famílias de um assentamento rural, no município de Luiziana (PR). A quantificação dos resíduos foi obtida por meio da pesagem mensal, durante três meses, amostrados em um total de 65 dias. $\mathrm{Na}$ composição gravimétrica dos resíduos foram encontrados materiais como papéis, plásticos, metais e vidros. A partir das análises quantitativas obteve-se a geração per capita de 0,052 kg. habitante..$^{-1}$ dia $^{-1}$ de resíduos inorgânicos.

Dias et al. (2007) relataram que, em trabalho realizado em Conceição do Almeida-BA, a geração per capita obtida na caracterização física dos resíduos domiciliares rurais, foi de 0,3 kg.habitante ${ }^{-1} \mathrm{dia}^{-1}$. Observaram ainda índices expressivos de matéria orgânica, o que corresponde a $64 \%$ do total. Os resíduos plásticos, metais, papéis e vidros perfizeram um total de $17 \%$. Na área rural do município de Montauri (RS), que possui uma população de 1.200 habitantes, registrou-se o recolhimento de 25 toneladas de resíduo seco em sete meses, nas 11 comunidades do interior (BREDA et al., 2004).

Em assentamento rural no município de Araras-SP, quanto à disposição final dos resíduos sólidos verificou-se que: $77,3 \%$ das famílias queimaram o lixo; 42,0\% lançaram-no nos arredores 
da casa; 29,6\% jogaram-no em valas no 'mato'; 6,8\% enterraram-no. Neste assentamento não é feita a coleta de resíduos pelo serviço público sendo que as famílias acabam dispondo os diferentes tipos de resíduos de diversas formas (ARAUJO et al., 2009). Finalmente, considera-se que existe uma escassez de dados, nacionais e internacionais, embasados cientificamente sobre a geração, composição gravimétrica e o gerenciamento de resíduos domiciliares rurais, apontando desta forma para uma necessidade premente de estudos sobre esta temática, possibilitando com isto, alicerçar sistemas de gerenciamento integrado de resíduos sólidos também nas áreas rurais.

\section{METODOLOGIA}

Para a realização do trabalho, foram consultados livros, artigos científicos, dissertações, teses e documentos oficiais que tratam do tema investigado. Também, dados estatísticos, documentos informativos, leis e outros necessários para compreender o sistema de resíduos sólidos em áreas urbanas e rurais a nível regional, nacional e internacional. O estudo realizado dessa problemática pressupõe em uma abordagem que contemple elementos da descrição de planejar a coleta seletiva de resíduos sólidos, a fim de proporcionar conhecimentos sobre as legislações vigentes da responsabilidade dos fabricantes pelo o ciclo global de vida de seus produtos, tanto em área urbana como também rural.

A utilização de documentos como artigos em pesquisas científicas foi destacado por Gil (2008). Segundo o autor, o uso de fontes documentais é capaz de proporcionar ao pesquisador dados em quantidade e qualidade suficientes para evitar a perda de tempo e o constrangimento que caracterizam muitas das pesquisas em que os dados são obtidos diretamente das pessoas. Além disso, em muitos casos só se torna possível realizar um determinado tipo de investigação por meio de documentos. Nos trabalhos públicos, buscou-se a informação referente à classificação, epidemiologia e toxicologia dos resíduos sólidos, a geração e reciclagem de resíduos nas áreas urbanas, o gerenciamento de resíduos sólidos e a responsabilidade no gerenciamento dos resíduos num panorama mundial, brasileiro e paranaense.

\section{RESULTADOS}

\section{Gerenciamento de Resíduos Sólidos}

Estudo realizado por Oliveira e Feichas (2007), em Encruzilhada do Sul-RS, apontaram que as famílias rurais dão o seguinte destino para os resíduos recicláveis domiciliares, considerando 'plásticos', 'latas', 'vidros' e 'papel', conforme demonstrado na tabela 1. O mesmo estudo também indicou que ao contrário do que ocorre na área urbana, os resíduos sólidos da área rural apresentam uma baixa quantidade de matéria orgânica, pois, devido à histórica falta de coleta e características próprias da área rural, os moradores destas áreas tendem a reaproveitar boa parte de seus resíduos orgânicos pela compostagem ou enterram os mesmos no solo. 
Tabela 1: Destinação de resíduos recicláveis domiciliares por famílias rurais do Município de Encruzilhada do Sul, Rio Grande do Sul.

\begin{tabular}{lllllll}
\hline \multirow{2}{*}{$\begin{array}{l}\text { RESíDUOS } \\
\text { RECILÁVEIS }\end{array}$} & QESTINAÇÃO (\%) & \multicolumn{2}{l}{} \\
\cline { 2 - 7 } & Queimados & Enterrados & \multirow{2}{*}{ Reciclados } & $\begin{array}{l}\text { Recolhidos } \\
\text { pela prefeitura }\end{array}$ & $\begin{array}{l}\text { Lançados ao } \\
\text { “mato" }\end{array}$ & $\begin{array}{l}\text { Outros } \\
\text { destinos }\end{array}$ \\
\hline Plásticos & 45 & 10 & 15 & 5 & 5 & 20 \\
Latas & 5 & 50 & 15 & 5 & 0 & 15 \\
Vidros & 0 & 35 & 20 & 5 & 0 & 30 \\
Papel & 65 & 10 & 10 & 10 & 0 & 15 \\
\hline
\end{tabular}

Fonte: Adaptado de Oliveira e Feichas (2007).

Para sanar o problema da geração e acumulação dos resíduos sólidos, é necessário planejar e gerenciar adequadamente ações que assegurem saúde, bem-estar, economia de recursos públicos e melhoria da qualidade de vida das gerações atuais e futuras. Pela grande diversidade quanto à origem dos resíduos, há necessidade de diferentes modelos de gerenciamento, visto que há possibilidade de reciclagem de parte dos resíduos sólidos, ou quando já em utilidade, promover o destino final adequado destes. Consoni et al. (2000) sugerem que as principais informações necessárias ao planejamento do gerenciamento dos resíduos municipais são: a taxa de geração por habitante $\left(\mathrm{kg}\right.$.habitante. ${ }^{-1}$ dia. $\left.{ }^{-1}\right)$, composição física, densidade aparente, umidade, teor de materiais combustíveis e incombustíveis, poder calorífico, composição química e teor de matéria orgânica.

O gerenciamento integrado dos resíduos deve começar pelo conhecimento de todas as características destes, pois muitos fatores influenciam sua composição, tais como: o número de habitantes do município, poder aquisitivo da população, condições climáticas, hábitos e costumes da população e nível educacional (JARDIM et al., 2010). Compreender de onde vieram as matérias-primas utilizadas, para onde irão os produtos fabricados, os subprodutos e os resíduos de processo, bem como os efeitos das emissões geradas para o meio ambiente, ou seja, entender o 'ciclo de vida' do bem produzido e consumido, é um passo de fundamental importância para o gerenciamento efetivo. Todo o produto consome algum recurso da natureza, ao mesmo tempo em que devolve ao meio ambiente algum tipo de emissão atmosférica, efluentes líquidos e/ou resíduos sólidos durante o seu processo produtivo (MOURAD et al., 2002).

Do ponto de vista do gerenciamento integrado de resíduos sólidos domiciliares, os materiais que compõem os resíduos gerados diariamente podem ser reaproveitados e/ou reciclados, ainda dentro de um processo de consumo. Nesse sentido, os conceitos de diversos administradores públicos, devem passar pelo ponto de vista social, econômico e ambiental. Por outro lado, para o empresário muitas vezes não é conveniente desenvolver ações de resgate destes materiais residuais. Assim, atualmente, a cada dia, novos tipos de embalagens e produtos descartáveis são gerados e terminam sua vida útil, em geral, no depósito municipal de resíduos sólidos urbanos ou na natureza pelo processo inadequado de destinação na área rural.

O Plano de Gerenciamento de Resíduos Sólidos (PGRS) de cada município deve conter e descrever as ações relativas ao seu manejo, contemplando os aspectos referentes à geração, separação, acondicionamento, transporte e disposição final com vistas à proteção da saúde publica e do meio ambiente. Para cada ação planejada devem ser elencadas todas as alternativas 
possíveis para a otimização das etapas evolvendo ações técnico-operacionais, educacionais e ambientais, tanto na área urbana, bem como na área rural. Porém, visualizam-se ações dispersas e soluções paliativas que descaracterizam o problema e inviabilizam o controle do processo final de gerenciamento dos resíduos sólidos domiciliares, quando idealmente, deveria haver estudos mais aprofundados, planejamento e soluções abrangentes para esta questão, do ponto de vista não só socioambiental como também econômico (CAMPOS \& BRAGA, 2005).

Diante destes fatos, é importante que o governo e a sociedade discutam novas atitudes, visando gerenciar de modo mais adequado a quantidade e a diversidade de resíduos que são gerados diariamente nos domicílios. É preciso colocar em prática a política dos ' 3 Rs' (Reduzir, Reutilizar e Reciclar), e não continuar a gerar descontroladamente mais resíduos, deixando que um outro agente assuma a responsabilidade de tratar e dispor adequadamente (CALDAS, 2007). Implantar o gerenciamento de resíduos sólidos não se resume apenas em fazer um plano de coleta seletiva, sem pensar no mercado de recicláveis na região, e muito menos sem envolver a comunidade. Devem ser atendidas questões de ordem cultural, socioeconômica, de saúde, educação e ambiental (LOPES, 2006). Um gerenciamento de resíduos sólidos deve ter por objetivo recuperar o valor dos materiais descartados, ocupando menos espaço e com menor impacto possível sobre o meio ambiente (MOURAD et al., 2002).

Visto que a geração não pode ser evitada, os resíduos resultantes devem ser reciclados para que a menor quantidade possível tenha como destino final os aterros sanitários e locais impróprios, como os 'lixões'. A reciclagem traz vantagens, pois além da economia de energia, de recursos fósseis e de água que seriam utilizados na manufatura de novos bens, ainda reduz os custos do transporte de deposição do lixo e a quantidade disposta nos aterros sanitários, prolongando o tempo de uso desses locais (BECK et al., 2009). Darolt (2002) aponta que os resíduos sólidos representam o fiel retrato da sociedade que os geram, e quando expostos nas vias públicas ou nas propriedades rurais, podem mostrar o nível de competência das pessoas ou empresas responsáveis por sua administração. A reavaliação de hábitos como a reeducação de valores poderá servir de trilha a um direcionamento, onde o reaproveitamento possa servir de exemplo para a redução de consumo de matéria-prima, onde a reciclagem é decisiva para novos hábitos ambientais e por consequência, para diminuição da utilização de recursos naturais e da degradação ambiental (SILVA \& TORRE, 2008).

As questões relacionadas aos resíduos sólidos, gerados nas cidades e no campo, tornaram-se problemas na maioria dos municípios brasileiros e no mundo todo, devido ao alto custo de implantação e manutenção dos sistemas de gerenciamento integrado dos resíduos sólidos. Avaliando aspectos como logística, condições climáticas e culturais locais, entre outras, em um país diverso com as dimensões do Brasil, e considerando o ciclo de vida de um produto do ponto de vista ambiental, conclui-se que pode ser mais viável a reutilização em determinados casos, e, em outros, pode ser mais vantajosa à reciclagem. Já o tratamento, além de ser uma questão que envolve implicações tecnológicas, é antes de tudo uma questão cultural. Muitas vezes a ausência de recursos humanos, como técnicos e engenheiros preparados para 
assessorar ou mesmo gerir os programas relativos aos resíduos, pode contribuir para um planejamento deficiente ou mesmo ineficaz. Por outro lado, a população, muitas vezes, não está preparada para portar-se como parte atuante e essencial dentro deste processo de planejamento integrado, ou ainda não foi devidamente orientada com relação ao tratamento dos resíduos (SANTOS, 2007).

Assim, o gerenciamento integrado pode ter efeitos altamente positivos nos aspectos econômicos, sociais e ambientais sendo umas das principais ferramentas para a preservação de fontes esgotáveis de matéria-prima, economia de energia, aumento da vida útil dos aterros sanitários, redução dos custos da disposição final dos resíduos e dos gastos com a saúde pública, geração de emprego e renda, educação ambiental, entre outros.

\section{Responsabilidades no Gerenciamento dos Resíduos: Panorama Mundial, Brasileiro e Paranaense}

As políticas de regulamentação de resíduos sólidos começaram a ser implementadas em todo o mundo a cerca de 100 anos atrás, sendo inicialmente destinadas a proteger a vida urbana (higiene e saúde) e, posteriormente, ampliando o seu conceito para a proteção ambiental das riquezas naturais utilizadas pela sociedade (ISWA, 2009). Vários países europeus como Alemanha, Holanda, Áustria, Espanha e Suécia, entre outros, introduziram nos últimos anos leis para reduzir a geração de resíduos, como vasilhames e embalagens. Na Suécia, por exemplo, as empresas são responsabilizadas pelo recolhimento de seus vasilhames de alumínio, papel, papelão, papel corrugado, plásticos, aço e vidro. O mesmo ocorre com jornais, folhetos publicitários, revistas e catálogos, além de pneus. Para racionalizar esse processo e tornar mais econômico o manejo da coleta e reciclagem, os geradores uniram esforços e se organizaram. A medida resultou numa redução significativa dos volumes de vasilhames e embalagens encaminhadas aos aterros sanitários, demonstrando a eficiência das leis que determinam a busca de soluções pelas empresas (IDEC, 2006).

Dias e Moraes (2008) apontaram que na Alemanha foi editada a Lei de Economia de Ciclo Integral e Gestão de Resíduos, em 1994, por meio da qual se responsabilizou o fabricante por todo o ciclo de vida de seu produto, desde a fabricação, passando pela distribuição e uso, até a sua eliminação. Também na França, em 1992, atribuiu-se aos embaladores a responsabilidade pela eliminação de resíduos de embalagens que resultam do consumo domiciliar de seus produtos. As empresas têm duas alternativas: adotar um sistema individual de depósito e retorno autorizado e controlado pelo Poder Público; e contribuir para um sistema coletivo que favoreça o desenvolvimento da coleta seletiva de embalagens, com adesão a uma entidade credenciada pelo Poder Público. Finalmente, a ISWA (2009) enfoca o problema dos resíduos sólidos, como sendo um objeto de novas iniciativas legislativas na Holanda e na Escócia.

Enquanto em alguns países da União Europeia o embate levou à legislação e à própria iniciativa empresarial a assumir a responsabilidade sobre todo o ciclo de vida dos produtos 
gerados, em outros países, ainda permanece-se um vácuo. No caso brasileiro, a própria sociedade, por meio de iniciativas como as das cooperativas assume o ônus e alguns bônus da reciclagem. Permanece o debate sobre o papel da indústria de embalagens, da indústria dos produtos embalados, dos governos e dos consumidores nesse processo (DIAS \& TEODÓSIO, 2006). No Brasil, de acordo com a Política Nacional de Resíduos Sólidos (Lei Federal $n^{\circ}$ 12.305/2010), incumbe-se ao Distrito Federal e aos Municípios 'a gestão integrada dos resíduos sólidos gerados nos respectivos territórios, sem prejuízo das competências de controle e fiscalização dos órgãos federais e estaduais, bem como da responsabilidade do gerador pelo gerenciamento de resíduos'. A Lei Federal n 11.445/2007 estabelece diretrizes nacionais para saneamento básico e define 'limpeza urbana e manejo de resíduos sólidos como sendo o conjunto de atividades, infraestruturas e instalações operacionais de coleta, transporte, transbordo, tratamento e destino final do lixo doméstico e do lixo originário da varrição e limpeza de logradouros e vias públicas'.

De acordo com a Lei de Crimes Ambientais, Lei Federal n 9.605/1998, prevê-se 'pena de um a cinco anos de reclusão para o agente que promover o lançamento de resíduos sólidos, líquidos ou gasosos, detritos ou substâncias oleosas em desacordo com as exigências legais, causando poluição de qualquer natureza que resulte ou possa resultar em danos à saúde humana, morte de animais ou destruição da flora'. No Estado do Paraná, a Lei n 12.493/1999 trata de estabelecer "princípios, procedimentos, normas e critérios referentes à geração, acondicionamento, armazenamento, coleta, transporte, tratamento e destinação final dos resíduos sólidos visando o controle da poluição, da contaminação e a minimização de seus impactos ambientais". Esta Lei foi um grande avanço sobre a questão de resíduos sólidos urbanos, visto que até o momento de sua promulgação, não havia legislação estadual pertinente ao assunto.

Ela ainda estabelece os impedimentos das formas de destinação final de resíduos sólidos, ficando proibidas, em todo o território do Estado do Paraná as seguintes formas de destinação de resíduos sólidos: 'lançamento 'in natura' a céu aberto, tanto em áreas urbanas como rurais; queima a céu aberto; lançamento em corpos d'água, manguezais, terrenos baldios, redes públicas, poços e cacimbas, mesmo que abandonadas; lançamento em redes de drenagem de águas pluviais, de esgoto, de eletricidade e de telefone'. Com relação à possibilidade de utilização do solo e subsolo como local de disposição dos resíduos sólidos, somente permite-se a utilização dos mesmos desde que com projetos específicos aprovados pelo Instituto Ambiental do Paraná (IAP). Porém, os municípios paranaenses, assim como a maioria dos municípios brasileiros, possuem uma carência efetiva de implementação de unidades de trabalho que recolham e destinem adequadamente os resíduos sólidos gerados em suas várias especificidades: urbano, rural, saúde, industrial, construção civil, vegetação e especial (pneus, baterias, lâmpadas, óleos, entre outros) (DUDAS et al., 2003).

Por outro lado, Dias e Moraes (2008) identificam que tem prevalecido o entendimento de que cabe apenas ao Poder Público, principalmente municipal, a destinação adequada dos resíduos sólidos gerados em seu território, tanto que existem centenas de ações judiciais visando 
compelir os municípios a implantar programas de coleta seletiva ou a construir aterros sanitários, usinas de reciclagem e compostagem e incineradores. Infelizmente, os municípios não têm suportado carregar o fardo que lhes têm sido imposto e não adotam as medidas que seriam adequadas ou mesmo aconselháveis para não provocar ou ao menos mitigar os danos ambientais.

Atualmente, o maior lucro com a introdução de produtos de vida curta e produção de embalagens descartáveis no mercado ficou para a empresa, mas o ônus da destinação final ficou somente a cargo do Poder Público, pois muitas empresas negligenciaram ou nem mesmo assumiram a sua parte de responsabilidade socioambiental. Nesse sentido, defende-se a responsabilização de todos que participam do ciclo completo que vai desde a fabricação de um produto até a sua destinação final como uma das soluções a serem adotadas para eliminar os danos ambientais decorrentes do manejo inadequado de resíduos sólidos. Portanto, almeja-se comprometer os fabricantes como co-responsáveis pelo ciclo global de vida dos seus produtos.

\section{CONCLUSÕES}

Há pouca informação, entre a sociedade e os próprios gestores públicos, acerca da destinação dos produtos gerados no pós-consumo, incluindo o seu ciclo de vida, das políticas públicas e da aplicação de Planos de Gerenciamento de Resíduos Sólidos, especialmente nas propriedades rurais, aumentando com isto a cada dia o passivo ambiental. Os resíduos sólidos recicláveis fazem parte do cotidiano das famílias e das comunidades na modernidade mundial, haja vista a inexistência de fronteiras geopolíticas, com a importação/exportação de produtos e globalização dos resíduos. Mais recentemente, a área rural por meio de inovações tecnológicas produtivas, adquiriu também mais acesso aos bens de consumo, antes apenas oferecidos ao público urbano, sendo este fato reflexo das mudanças na formação da economia da agropecuária com a implementação da diversificação de explorações e novas rendas rurais e não-rurais.

Apesar de existirem, ao nível internacional, alguns trabalhos em pequenos municípios inseridos em matrizes agropecuárias, são raros os trabalhos que abordam os resíduos sólidos domiciliares recicláveis na propriedade rural, fazendo-se necessários mais estudos que possibilitem o conhecimento de seu passivo ambiental. No que tange aos resíduos recicláveis domésticos é imprescindível diagnosticar as suas características físico-químicas e quantidades per capita ao longo das estações do ano para possibilitar ações de gerenciamento que produzam efeitos sociais, ambientais e econômicos na melhoria da qualidade de vida individual e coletiva.

Os municípios brasileiros não dispõem de infraestrutura adequada para execução da coleta e, principalmente, não possuem informações precisas da periodicidade, qualidade e quantidade dos resíduos gerados nas áreas rurais para implementar um efetivo plano de gestão integrada. Finalmente, recomendar uma nova regulamentação legal no país que contemple informações nas embalagens sobre o ciclo de vida dos resíduos no meio ambiente é fator decisivo 
no processo de conscientização da sociedade e, especialmente, no compartilhamento de responsabilidades, vital para o adequado gerenciamento dos resíduos sólidos.

\section{REFERÊNCIAS}

ABDULI, M. A.; SAMIEIFARD, R. E.; ZADE, J. G. M.. Rural solid waste management. International Journal of Environmental Research, Tehran, v.2, n.4, p.425-430, 2008.

ARAUJO, K. C. S.; BORGES, J. R. P.; FERREIRA, P. F.. Um estudo da qualidade do saneamento ambiental rural: fator para o desenvolvimento local sustentável. In: CONGRESSO DE MEIO AMBIENTE DA ASSOCIAÇÃO DE UNIVERSIDADES GRUPO DE MONTEVIDÉU. 6. Anais. São Carlos: UFSCAR, 2009.

BECHARA, E. J. H.. Oxidative stress in acute intermittent porphyria and lead poisoning may be triggered by 5-aminolevulinic acid. Brazilian Journal of Medical and Biological Research, Brasilia, v.29, p. 841-851, 1996.

BECK, C. G.; ARAÚJO, A. C.; CÂNDIDO, G. A.. Problemática dos resíduos sólidos urbanos do município de João Pessoa: Aplicação do modelo P-E-R. Revista Eletrônica UEPB, v.8, n.3, p.1-15, 2009.

BREDA, F.J.; FELIPPE, S. M. C.; MORETTO, A. J. F.. Coleta seletiva do lixo: um processo de educação e saneamento ambiental. Caxias do Sul: Empresa de Assistência Técnica e Extensão Rural, 2004.

CALDAS, A. H. M. C.. Análise da disposição de resíduos sólidos e da percepção dos usuários em áreas costeiras - um potencial de degradação ambiental. Monografia (Especialização em Gerenciamento e Tecnologia Ambiental) - Universidade Federal da Bahia, Salvador 2007.

CAMPOS, J. O.; BRAGA, R.. Gestão de resíduos: valorização e participação. Rio Claro: Ed. LPM/IGCE/UNESP, 2005.

CAPATINA, C.; SIMONESCU, C. M.. Management of waste in areas of Gorj county, Romania. Environmental Engineering and Management Journal, v.7, n. 6, p.717-723, 2008.

CASTAGNARI, E.. Panorama dos resíduos sólidos no Brasil 2009. São Paulo: ABRELPE, 2010.

CHUNG, S. S.; POON, C. S.. A comparison of waste-reduction practices and new environmental paradigm of rural and urban Chinese citizens. Journal of Environmental Management, v.62, p.3-19, 2001.

CONSELHO INTERMUNICIPAL DE SANEAMENTO AMBIENTAL (CISAN). Manual de saneamento rural. Uberlândia: CISAM / AMVAP, 2006.

CONSONI, A. J.; PEREZ, C. S.; CASTRA A. P.. Origem e Composição do Lixo. In: VILHENA, A. (Ed.). Lixo municipal, manual de gerenciamento. São Paulo: CEMPRE, 2000.

DAROLT, M. R.. Lixo rural: Entraves, estratégias e oportunidades. Curitiba, IAPAR, 2002.

DIAS, J. A.; MORAES, A. M. F.. Os Resíduos sólidos e a responsabilidade ambiental pós-consumo. 2 ed. Marilia: MPF, 2008.

DIAS, S. L. F. G.; TEODÓSIO, A. S. S.. Reciclagem do PET: desafios e possibilidades. In: ENCONTRO NACIONAL DE ENGENHARIA DE PRODUÇÃO. 26. Anais. Fortaleza: ABEPRO, 2006.

DIAS, S .M. F.; VAZ, L. M. S.; CAMPOS, A. C. A.. Educação ambiental e mobilização comunitária para implantação do gerenciamento integrado de resíduos sólidos em uma comunidade rural do Estado da Bahia. In: CONGRESSO BRASILEIRO DE ENGENHARIA SANITÁRIAE AMBIENTAL, 24. Anais. Rio de Janeiro: ABES, 2007.

DUDAS, L.; MITTELSTAEDT, C.; MUELLER, R. L.. Política de resíduos sólidos do estado do Paraná. Programa Desperdício Zero. Curitiba: SEMA, 2003.

EL-MESSERY, M. A.; ISMAIL, G. A.; ARAFA, A. K.. Evaluation of municipal solid waste management in Egyptian rural areas. Journal of the Egyptian Public Health Association, v.84, n.1-2, p.51-70, 2009. 
FINATTO, R. A.; SALAMONI, G.; CUNHA, A. P. A.; COSTA, A. J. V.; PANIS, M.; ALEXIS, A. A.;

BARCELLOS, D. C.. A gestão do lixo no espaço rural: uma experiência de educação na Escola Garibaldi, Colônia Maciel, Pelotas. In: CONGRESSO DE INICIAÇÃO CIENTÍFICA, 14. Anais. Pelotas: UFPel, 2005.

GIL, A. C.. Métodos e técnicas de pesquisa social. São Paulo: Atlas, 2008.

HERMES-LIMA, M.; PEREIRA, B.; BECHARA, E. J. H.. Are free radicals involved in lead poisoning? Xenobiotica, v.21, p.1085-1090, 1991.

ISWA. INTERNATIONAL SOLID WASTE ASSOCIATION. Waste and climate change. Vienna: Iswa White Paper, 2009.

JAKUS, P. M.; TILLER, K. H.; PARK, W. M.. Explaining rural household participation in recycling. Journal of Agricultural and Applied Economics, Tennessee, p.141-148, 1997.

JARDIM, N. S.; WELLS, C.; CONSONI, A. J.; AZEVEDO, R. M. B.. O gerenciamento integrado do lixo municipal. In: VILHENA, A.. (Ed.) Lixo municipal: manual de gerenciamento integrado. São Paulo: CEMPRE, 2010.

LACOSTE, E.; CHALMIN, P.. From waste to resource: 2006 world waste survey. Paris: Economica editions, 2006.

LOPES, L.. Gestão e gerenciamento integrado de resíduos sólidos urbanos- alternativas para pequenos municípios. Dissertação (Mestrado em Geografia Humana) - Faculdade de Filosofia, Letras e Ciências Humanas da Universidade de São Paulo, São Paulo, 2006.

MARTINS, L. F. V.; ANDRADE, H. H. B.; PRATES, K. V. M. C.. Diagnóstico quali-quantitativo dos resíduos sólidos domiciliares gerados no assentamento rural Luz, Luiziana-Paraná. Revista Saúde e Biologia, v.4, n.2, p.14-20, 2009.

MONTEIRO, J. H. P.. Manual de gerenciamento integrado de resíduos sólidos. Rio de Janeiro: IBAM, 2001.

MOURAD, A. L.; GARCIA, E. E. C.; VILHENA, A. Avaliação do ciclo de vida: princípios e aplicações. Campinas: CETEA/CEMPRE, 2002.

OLIVEIRA, K. V. V.; FEICHAS, S. A. Q.. Subsídios a proposta de gerenciamento de resíduos sólidos em área rural: caso de Encruzilhada do Sul (RS). In: ENCONTRO NACIONAL SOBRE GESTÃO EMPRESARIAL E MEIO AMBIENTE, 4. Anais. Curitiba: Universidade Positivo, 2007.

OLYMPIO, K. P. K.; OLIVEIRA, P. V.; NAOZUKA, J.; CARDOSO, M. R. A.; MARQUES, A. F.; GÜNTHER, W. M. R.; BECHARA, E. J. H.. Surface dental enamel lead levels and antisocial behavior in Brazilian adolescents. Neurotoxicology and Teratology, v.32, p.273-279, 2010.

SANTOS, M. V. B.. A disposição dos resíduos sólidos em Cruz das Almas: estudo dos bairros Dr. Lauro Passos, Ana Lúcia e Tabela. Dissertação (Mestrado em Cultura, Memória e Desenvolvimento Regional) - Universidade do Estado da Bahia, Santo Antonio de Jesus, 2007.

SILVA, E. A.; TORRE, M. B. R.. Disposição de resíduos sólidos urbanos: um estudo de caso a partir das concepções de moradores das comunidades de Moranguinho/Metrô, Areia Branca (RN). Revista Brasileira de Gestão Ambiental, v.2, n.1, p.5-25, 2008.

STOKOE, J.; TEAGUE, E.. Integrated solid waste management for rural areas: a planning tool kit for solid waste managers. Washington: USDA-Rural Utilities Service, 1995. 